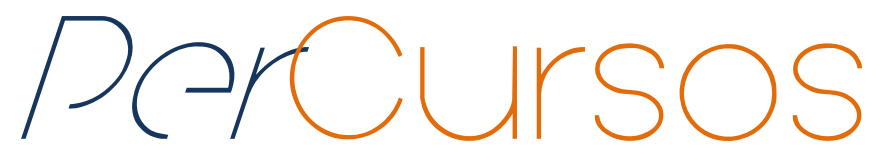

\title{
Clandestinidade, omissão e complacência: a ocupação ilegal da Comunidade Vila do Arvoredo em Florianópolis
}

\begin{abstract}
Resumo
Este artigo pretende abordar a ocupação ilegal da Comunidade Vila do Arvoredo, localizada no bairro Ingleses, Município de Florianópolis. Trata de apresentar a legislação específica aplicável ao tema expondo a dificuldade de entrelaçamento entre os poderes públicos para a solução dos problemas relacionados à ocupação ilegal, proteção ambiental e garantia de direitos constitucionais. Com esse propósito, refere-se às principais questões acerca da ocupação da área, traçando uma relação entre seu histórico e a necessidade de reflexão que considere a união de esforços para a efetiva regularização ou remoção e reassentamento fundiário das famílias, além da inclusão territorial e proteção ambiental. Propõe, como referencial teórico, a utilização de conceitos ligados à aplicação de políticas públicas voltadas ao ambiente natural e urbano no Brasil, como os de áreas de proteção permanente, poder de polícia, regularização fundiária, pacto federativo, propriedade, inclusão territorial, planejamento e gestão. Para o levantamento de dados foram utilizadas a pesquisa bibliográfica e uma abordagem empírica da comunidade realizada de maneira exploratória e preliminar no ano de 2016. A expectativa é contribuir para o aprofundamento das questões que envolvem ocupações ilegais em áreas de preservação no sentido de reafirmar a importância da gestão e do trabalho conjunto dos poderes, não obstante o esquema de competências constitucional existente, no intuito de garantir o meio ambiente ecologicamente equilibrado, o direito à moradia e à propriedade.
\end{abstract}

Elisa Quint de Souza de Oliveira

Doutoranda e Mestre em

Planejamento Territorial e

Desenvolvimento Socioambiental pela Universidade do Estado de

Santa Catarina - UDESC, Advogada.

elisa21355@gmail.com

\section{Pedro Martins}

Doutor em Antropologia pela

Universidade de São Paulo - USP,

Professor do Programa de Pós

graduação em Planejamento

Territorial e Desenvolvimento

Socioambiental - PPGPLAN da

Universidade do Estado de Santa

Catarina - UDESC.

weltermartins@yahoo.com.br

Palavras-chave: Regularização Fundiária. Ocupação llegal. Inclusão Territorial. Posse de Terra - Florianópolis-SC, Proteção Ambiental.

\section{Para citar este artigo:}

DE OLIVEIRA, Elisa Quint de Souza; MARTINS, Pedro. Clandestinidade, omissão e complacência: a ocupação ilegal da Comunidade Vila do Arvoredo em Florianópolis. Revista PerCursos, Florianópolis, v. 19, n.40, p. 265 - 284, maio/ago. 2018.

\section{DOI: 10.5965/1984724619402018265}

http://dx.doi.org/10.5965/1984724619402018265 


\title{
Clandestinity, omission and complacence: the illegal occupation of the Vila Do Arvoredo Community in Florianópolis
}

\begin{abstract}
This article intends to address the illegal occupation of the Arvoredo Community, located in Praia de Ingleses, Municipality of Florianópolis. It proposes to present the specific legislation applicable to the subject by exposing the difficulty of interweaving between the public authorities to solve the problems related to illegal occupation, environmental protection and the guarantee of constitutional rights. With this purpose, it refers the main questions about the occupation of the area, drawing a relation between its history and the need for reflection that considers the union of efforts for the effectiveness of the regularization or removal and resettlement of families, as well as territorial inclusion and environmental protection. It proposes, as a theoretical reference, the use of concepts related to the application of public policies aimed at the natural and urban environment in Brazil, such as permanent protection areas, police power, land regularization, federative pact, property, territorial inclusion, planning and management. For the data collection, we used bibliographical research and an empirical approach of the community carried out in an exploratory and preliminary way in the year 2016. The expectation is to contribute to the deepening of the issues involving illegal occupations in preservation areas in order to reaffirm the importance of the management and the joint work of the powers notwithstanding the existing constitutional competency scheme in order to guarantee the environment ecologically balanced, the right to housing and property.
\end{abstract}

Keywords: Land Regularization. Illegal Occupation. Territorial Inclusion. Land Tenure Environmental Protection. 
Quando adquiriu seu imóvel sobre as dunas do Santinho, balneário valorizado, ao norte do município de Florianópolis, Ilha de Santa Catarina, há quase 20 anos, João da Silva ${ }^{1}$ acreditou que estava realizando um bom negócio, muito embora the parecesse estranho que a casa contivesse grande quantidade de areia proveniente das dunas vizinhas. Animado com a perspectiva de proporcionar melhores condições de vida à família, João deixou para trás, sem receio, o passado sofrido no sudoeste do Paraná, entregando o dinheiro ao vendedor e recebendo um simples recibo comprobatório da avença. Quando a casa que comprara foi, naturalmente, tomada pelas dunas percebeu que as mudanças seriam constantes e que teria que reacomodar a família de tempos em tempos até que o poder público tomasse uma atitude e os tirasse dali. Começou, na oportunidade, a compreender as razões pelas quais a terra era tão barata e a estranhar o nome que se dava para aquela área tomada de areia fofa. João da Silva percebeu que as outras famílias, assim como a dele, se submetiam às mesmas condições e que a ocupação sobre aquelas terras instáveis só crescia. Em sua compreensão, como também na de outros tantos moradores das areias, a definição da área não poderia ser outra: Área Proibida para Pobre - APP ${ }^{2}$.

A vizinha de João da Silva, Maria José, que também é moradora da comunidade há quase 20 anos e é oriunda da mesma região que seu vizinho, mudou-se quatro vezes em razão do movimento das dunas. Depois que enviuvou, Maria passou a catar lixo para criar os 10 filhos. A primeira casa que comprou não possuía banheiro e era formada de estrutura e telhado, sem as paredes.

Passados tantos anos após a primeira ocupação, João da Silva e Maria José sairiam de lá, se pudessem, mas concordam que viver fora da comunidade é caro. Atualmente, compreendem o que é uma área de preservação permanente e as razões pelas quais a ocupação é proibida. Porém, questionam o poder público municipal sobre o direito à cidade, à educação, à saúde e outros tantos, uma vez que não possuem, sequer, os serviços de infraestrutura básica como energia elétrica ou distribuição de água. Contestam o poder público municipal, apesar de estarem em área proibida, porque entendem que não invadiram as terras. Eles, de fato, compraram de alguém que afirmava as possuir. Ao longo dos anos e diante da vida nômade que levam fugindo

\footnotetext{
${ }^{1}$ Os nomes citados são fictícios.

${ }^{2}$ Interpretação dada pelos moradores da Comunidade do Arvoredo para a sigla APP - Área de Preservação Permanente, constante no Código Florestal Nacional, cujo uso é limitado e por vezes proibido pelo poder público no intuito de assegurar o meio ambiente natural equilibrado.
} 
das areias a cada mudança de vento, decidiram que só sairão de lá quando o Município lhes der condições dignas de moradia. Afinal, segundo eles, alguém precisa arcar com o ônus da ausência de cuidado com as áreas protegidas legalmente, áreas essas que eles nem sabiam que existiam.

A comunidade Vila do Arvoredo, situada na praia de Ingleses, no município de Florianópolis, está localizada a $35 \mathrm{~km}$ do centro da cidade na porção norte da llha de Santa Catarina. O bairro Ingleses resulta em grande medida de um processo crescente de ocupação iniciado em meados dos anos 1970 associado à execução dos aterros das baías norte e sul, à construção das pontes Colombo Salles e Pedro Ivo Campos e aos projetos de incentivo ao turismo. Grando (2011, p. 125) faz referência ao período:

Entre os anos de 1976 e 1994, período de expansão urbana da cidade e de transformação dos balneários não apenas em turismo, mas em área de moradia, refletiu-se em acelerado processo de urbanização de Ingleses. $O$ adensamento, no começo, foi linear, acompanhando a Estrada Geral que liga Ingleses a Santinho. Posteriormente expandiu-se pelas servidões surgidas perpendicularmente à via principal.

Conhecida também como "Favela do Siri", uma vez que está localizada no final da Rua do Siri, a Comunidade Vila do Arvoredo é originária da década de 1980 quando algumas famílias advindas, em sua maioria, do sudoeste paranaense, à procura de melhores condições de vida, compraram porções de terra de habitantes nativos, sem qualquer registro cartorário, próximas ou mesmo sobre as dunas da praia, passando a ocupar área de preservação permanente. ${ }^{3} \mathrm{~A}$ ocupação clandestina ${ }^{4}$ permaneceu por mais de três décadas sem que tenham sido removidas as famílias em prol do interesse coletivo pelo meio ambiente ecologicamente equilibrado ${ }^{5}$ ou pela própria situação de precariedade em que se encontram. Em 1995, apenas 30 famílias ocupavam as dunas de Ingleses. Com a intensificação das ocupações, 10 anos depois, 221 famílias já ocupavam o local, segundo Grando (2011, p. 126).

Não obstante o fato de não possuírem qualquer documento que legitime a permanência na área ocupada, as características do local - dunas que se movimentam ao sabor do vento -

\footnotetext{
${ }^{3}$ Área de preservação permanente, segundo o Art. $3^{\circ}$, inc. II da Lei no 12.651 de 25 de maio de 2012, é a "área protegida, coberta ou não por vegetação nativa, com a função ambiental de preservar os recursos hídricos, a paisagem, a estabilidade geológica e a biodiversidade, facilitar o fluxo gênico de fauna e flora, proteger o solo e assegurar o bem-estar das populações humanas".

${ }^{4}$ Ocupação clandestina é aqui entendida como aquela realizada sem qualquer tipo de projeto ou intervenção do poder público.

${ }^{5}$ Entende-se por Meio Ambiente ecologicamente equilibrado, o requisito essencial para um modo de vida digno, elevado ao status de direito fundamental.
} 
intensificam o problema da ocupação clandestina. Casas são construídas e remontadas a todo o momento em razão da modificação da concentração das areias. As ligações de energia são clandestinas, não há distribuição de água tampouco saneamento básico.

A perpetuação da situação absolutamente ilegal, seja pela ocupação de área de preservação, seja pela situação irregular das moradias, somada ao adensamento cada vez mais expressivo de ocupantes advindos, atualmente, de muitas outras regiões do país, intriga e assombra a população. Qual seria o motivo ou os motivos pelos quais o problema, gravíssimo dos pontos de vista ambiental, urbano, jurídico e administrativo, além de não ser solucionado, aparenta ser cada vez maior e mais complexo?

O ponto de partida para a resposta acredita-se, está na discussão de conceitos ligados à aplicação de políticas públicas voltadas ao ambiente natural e urbano no Brasil - como os de áreas de proteção permanente, poder de polícia, regularização fundiária, pacto federativo, propriedade, inclusão territorial, planejamento e gestão.

\section{Fundamentação teórica}

Partimos de uma reflexão mais ampla sobre os descaminhos da regularização fundiária em áreas urbanas sem adentrar nas diferentes agruras do grupo social integrado por João e Maria buscando inventariar os principais aspectos críticos e refletir sobre o território da Favela do Siri/ Vila do Arvoredo frente à legislação. Esse intento constitui o principal objetivo deste trabalho. Para tanto, resgatam-se os conceitos ligados à aplicação de políticas públicas voltadas ao ambiente natural e urbano no Brasil - como os de áreas de proteção permanente, poder de polícia, regularização fundiária, pacto federativo, propriedade, inclusão territorial, planejamento e gestão.

No que se refere ao meio ambiente natural, especificamente, é evidente a infração às normas que proíbem a ocupação em área de preservação permanente. Meirelles (2007, p._735) faz referência à importância dessas áreas:

A vegetação, nativa ou não, e a própria área são objeto de preservação não só por si mesmas, mas pelas suas funções protetoras das águas, do solo, da biodiversidade (aí compreendido o fluxo gênico da fauna e da flora), da paisagem e do bem-estar humano. A área de preservação permanente-APP não é um favor da lei, é um ato de inteligência social, e é de fácil adaptação às condições ambientais. 
As dunas ocupadas em Ingleses são bens de uso comum do povo ${ }^{6}$, ainda que possa existir reivindicação de direitos particulares sobre elas, uma vez que são consideradas acrescidos de marinha ${ }^{7}$, independentemente de qualquer registro público. A reivindicação de propriedade sobre dunas, portanto, é discutível uma vez que, por sua natureza, nunca constituíram terras agricultáveis e, em razão deste fato, não poderiam fazer parte das terras tidas como devolutas ${ }^{8}$ pelo Estado.

O município de Florianópolis possui o Decreto nº 112, de 31 de maio de 1985, que tombou as dunas de Ingleses como patrimônio natural e paisagístico do Município proibindo quaisquer atividades ou edificações.

Os municípios brasileiros podem assegurar o patrimônio paisagístico e natural das dunas com base no Art. 180, da Constituição Federal', e na legislação específica sobre proteção do patrimônio histórico, artístico e natural, além da Lei $\mathrm{n}^{\circ}$ 12.651, de 25 de maio de 2012, Código Florestal que, no Art. $4^{\circ}$, inc. $\mathrm{V}$, considera de preservação permanente a vegetação situada nas restingas como fixadoras de dunas. $\mathrm{O}$ art. $8^{\circ}, \S 1^{\circ}$ da mesma norma, prevê que a supressão de vegetação nativa protetora de dunas somente poderá ser autorizada em caso de utilidade pública.

Florianópolis previu, ainda, em seu atual Plano Diretor, Lei Complementar nº 482, de 17 de janeiro de 2014 -, previsão esta, inclusive, que esteve presente também no Plano Diretor anterior (Lei Complementar $n^{\circ} 2.193$ de 1985) as dunas como áreas de preservação permanente:

Art. 43. As Áreas de Preservação Permanente (APP) no município de Florianópolis são as zonas naturais sob a proteção do Poder Público, cobertas ou não por vegetação nativa, com a função ambiental de preservar os recursos hídricos, a paisagem, a estabilidade geológica e a biodiversidade, facilitar o fluxo gênico de fauna e flora, proteger o solo e assegurar o bem-estar das populações

\footnotetext{
${ }^{6}$ Bens de uso comum do povo são destinados à utilização geral pelos indivíduos, em igualdade de condições, independentemente do consentimento individualizado por parte do Poder Público.

${ }^{7}$ Acrescidos de marinha são os terrenos que tiverem se formado, natural ou artificialmente, para o lado do mar ou dos rios e lagoas em seguimento nos terrenos de marinha, segundo o Art. $2^{\circ}$ do Decreto-Lei $n^{\circ}$ 3.438, de 17 de julho de 1941 .

${ }^{8}$ Terras devolutas são terras públicas, sem destinação pelo Poder Público, que nunca integraram patrimônio particular ainda que estejam irregularmente sob sua posse. $O$ termo remete ao primeiro regime de terras do Brasil que consistia no Regime das Sesmarias. Naquele regime, as terras que não eram cultivadas pelos posseiros eram devolvidas à Coroa.

${ }^{9}$ Art. 180 da Constituição Federal: a União, os Estados, o Distrito Federal e os Municípios promoverão e incentivarão o turismo como fator de desenvolvimento social e econômico.
} 
humanas [...] $/ \S 1^{\circ}$ Incluem-se nas Áreas de Preservação Permanente os seguintes ecossistemas e espaços naturais cuja proteção tenha sido instituída através de classificação dos mapas do zoneamento das leis anteriores, observadas no presente Plano Diretor: I - dunas móveis, fixas e semi-fixas.

Deste modo é possível perceber a desconsideração das obrigações contidas nas normas com a ocupação clandestina que constitui a Vila do Arvoredo não obstante o poder de polícia inerente ao poder público municipal, cujo conceito e destinação são fundamentais para compreender a importância de seu exercício.

O conceito legal de poder de polícia está presente no art. 78 do Código Tributário Nacional, Lei $\mathrm{n}^{\circ}$ 5.172, de 25 de outubro de 1966:

Considera-se poder de polícia atividade da administração pública que, limitando ou disciplinando direito, interesse ou liberdade, regula a prática de ato ou abstenção de fato, em razão de interesse público concernente à segurança, à higiene, à ordem, aos costumes, à disciplina da produção e do mercado, ao exercício de atividades econômicas dependentes de concessão ou autorização do Poder Público, à tranquilidade pública ou ao respeito à propriedade e aos direitos individuais ou coletivos.

Importante asseverar que o poder de polícia não é uma faculdade do poder público uma vez que deve ser obrigatoriamente aplicado. Sobre o tema, assim se manifesta Dawalibi:

Desde logo, pode-se afirmar que, certamente, não se trata de faculdade. Aliás, não se deve olvidar o Princípio da Obrigatoriedade do Desempenho da Atividade Pública, uma vez que fazer valer o cumprimento da legislação não se coloca ao Estado como uma faculdade ou uma discricionária manifestação de vontade. (DAWALIBI, 1999, p. 92)

Assim, a Constituição da República, ao impor ao poder público a defesa do meio ambiente, deixa claro que o exercício do poder de polícia é obrigatório. Compreende-se assim que o Município de Florianópolis teria a legitimidade necessária para pôr fim à situação de ilegalidade em que se encontram as famílias da Vila do Arvoredo sem ser obrigado a se utilizar do Poder Judiciário.

Antes do advento da Constituição Federal de 1988 já havia no Brasil a formulação de uma Política Nacional do Meio Ambiente, instituída pela Lei $n^{\circ}$ 6.938, de 31 de agosto de 1981. 
Portanto, é possível afirmar que o exercício do poder de polícia faz parte dos instrumentos para a aplicação de Política Nacional do Meio Ambiente.

Sendo obrigatória sua aplicação, o poder de polícia municipal, no caso da ocupação em área de preservação permanente e também da construção irregular, não poderia ser preterido seja por falta de recurso ou de infraestrutura ou qualquer outra razão uma vez que nenhuma alegação justificaria o seu não exercício.

Do mesmo modo que o poder de polícia pode ser entendido como um dos instrumentos para a Política Nacional do Meio Ambiente, tem-se que a regularização fundiária é uma ferramenta hábil à garantia do acesso à terra em condições adequadas e instrumento da Política Urbana.

A primeira tentativa de regularização fundiária no Brasil remonta ao ano de $1850^{10}$, com a instituição de um novo regime jurídico que se seguiu às sesmarias ${ }^{11}$ : o regime das posses, cuja intenção era de que o primeiro posseiro, após explorar a terra, realizasse benfeitorias e legalizasse, pelo reconhecimento da posse, sua situação fundiária.

A regularização fundiária hoje é entendida, no entanto, segundo a Lei Federal n 11.977, de 7 de junho de $2009^{12}$, como:

O conjunto de medidas jurídicas, urbanísticas, ambientais e sociais que visam à regularização de assentamentos irregulares e à titulação de seus ocupantes, de modo a garantir o direito social à moradia, o pleno desenvolvimento das funções sociais da propriedade urbana e o direito ao meio ambiente ecologicamente equilibrado.

A Lei Federal $\mathrm{n}^{\circ}$ 11.977, de 7 de junho de 2009, no entanto, foi alterada substancialmente pela Medida Provisória $\mathrm{n}^{\circ} 759$, de 22 de dezembro de $2016^{13}$, que veio complementar e supostamente facilitar a aplicação dessa norma com previsões de ordem prática de cunho administrativo e operacional para o alcance dos objetivos da legislação pertinente.

\footnotetext{
${ }^{10}$ Lei n ${ }^{\circ} 601$, de 18 de setembro de 1850 . Dispõe sobre as terras devolutas no Brasil.

${ }^{11}$ Nome fornecido às terras, na época do império português, que eram cedidas por Portugal aos agricultores para plantio. Até 1850, o Brasil manteve o regime das sesmarias instituído pelo Império Português por volta de 1530.

${ }^{12}$ Lei Federal $n^{\circ}$ 11.977, de 7 de julho de 2009. Dispõe sobre o Programa Minha Casa, Minha Vida - PMCMV e a regularização fundiária de assentamentos localizados em áreas urbanas; altera o Decreto-Lei $\mathrm{n}^{\circ} 3.365$, de 21 de junho de 1941, as Leis $\mathrm{n}^{\mathrm{os}} 4.380$, de 21 de agosto de 1964, 6.015, de 31 de dezembro de 1973 , 8.036, de 11 de maio de 1990, e 10.257, de 10 de julho de 2001, e a Medida Provisória no $2.197-43$, de 24 de agosto de 2001; e dá outras providências. $\mathrm{n}^{\circ} 3.930$ de 06 de janeiro de 2006.

${ }^{13}$ Medida Provisória $n^{\circ} 759$, de 22 de dezembro de 2016. Dispõe sobre a regularização fundiária rural e urbana e dá outras providências.
} 
Posteriormente, a citada norma deu lugar à Lei Federal $n^{\circ} 13.465$, de 11 de julho de $2017^{14}$, atualmente em vigor. A norma possui a pretensão de facilitar a escrituração de terras de ocupantes supostamente ilegais prevendo a possibilidade de regularização rural ou urbana, além de instituir mecanismos de alienação de imóveis da União para fins de regularização fundiária.

A regularização fundiária tem papel importante no contexto da ocupação da Vila do Arvoredo considerando que poderia ser aplicada em área de preservação permanente mediante estudo ambiental previsto na mesma norma que a regula. Ressalta-se que essa é uma exceção à regra contida para salvaguardar as áreas de proteção permanente existentes na legislação brasileira desde 1965 e que permaneceu vigente mesmo com as alterações legislativas ocorridas em 2017.

O fato de a comunidade estar alocada sobre dunas, no entanto, faz da aplicação desse instrumento um desafio, sopesando que a ocupação pode ser considerada de risco por conta de problemas de saúde que o contato direto com a areia proporciona e mediante a mobilidade da areia em razão dos ventos. Vale ressaltar, porém, que muito embora a maioria das casas da comunidade esteja sobre as dunas, uma pequena parte encontra-se em seu entorno, o que talvez possibilitasse a aplicação do instrumento jurídico referido.

A Constituição Federal, por sua vez, elegeu a forma federativa de Estado em seu artigo $60, \S 4^{\circ}$, I, fazendo valer o Pacto Federativo que apresentou, desde a criação, um movimento de descentralização na direção do poder local que significou uma transferência de recursos e poder aos municípios. Ainda na esfera das Políticas Urbanas, o Pacto Federativo se apresenta como conceito norteador para a compreensão da necessidade da participação efetiva do município na gestão.

Quanto à organização do poder político estatal, em respeito ao Pacto Federativo, Silva afirma:

O poder político, uno, indivisível e indelegável, se desdobra e se compõe de várias funções, fato que permite falar em distinção das funções, que fundamentalmente são três: a legislativa, a executiva e a jurisdicional. A função legislativa consiste na edição de regras gerais, abstratas, impessoais e inovadoras da ordem jurídica, denominadas leis. A função executiva resolve os problemas concretos e individualizados, de acordo com as leis; não se limita à simples execução de leis, como às vezes se diz; comporta prerrogativas e nela

\footnotetext{
${ }^{14}$ Lei Federal $n^{\circ}$ 13.465, de 11 de julho de 2017. Dispõe sobre a regularização fundiária rural e urbana e dá outras providências.
} 
entram todos os atos e fatos jurídicos que não tenham caráter geral e impessoal; por isso, é cabível dizer que a função executiva se distingue em função de governo, com atribuições políticas, co-legislativas e de decisão, e função administrativa, com suas três missões básicas: intervenção, fomento e serviço público. (SILVA, 2009, p. 108)

A harmonia entre os poderes, portanto, mostra-se absolutamente necessária para que haja respeito às prerrogativas e faculdades a que todos têm direito. Assim, os trabalhos desenvolvidos pelo Legislativo, Executivo e Judiciário só serão eficientes se os órgãos se subordinarem ao princípio da harmonia. Esse princípio não significa o domínio de um pelo outro, tampouco a usurpação de atribuições, mas a colaboração e controle recíproco para evitar distorções de competência.

No caso ora estudado é possível atestar que a falta do exercício de funções do Poder Executivo - como exemplo, a remoção das famílias a contento, quando a ocupação ainda era mínima - leva ao Poder Judiciário uma série de questões cuja natureza não lhe compete ou não Ihe competiria, caso as atribuições dos órgãos competentes fossem cumpridas, segundo o esquema constitucional da separação dos poderes.

No que se refere ao princípio da separação dos poderes, vale citar Dalvi (2008, p. 44) quando afirma que:

O sistema de freios e contrapesos (checks and balances) pode ser definido como a imposição de limites entre os poderes para que um não ultrapasse de forma arbitrária a esfera do outro. [...] É de fácil entendimento que o sistema de contrapesos é a constatação de que a nenhum poder é dada legitimidade para agir sem a fiscalização de outro poder. O sistema de freios e contrapesos tem a finalidade de evitar arbitrariedades cometidas por qualquer esfera de poder. Assim, em regra, as decisões judiciais não podem entrar no mérito administrativo, embora excepcionalmente possa ser feito tal controle.

Não obstante o fato de se tratar de ocupação ilegal em área de preservação permanente, é certo que deve ser considerado o direito à propriedade a ser mencionado em harmonia com o princípio da função social sendo, naturalmente, função do Direito criar condições para a valorização da cidadania e promoção da justiça social.

Vista como uma garantia fundamental do homem e prevista constitucionalmente, a propriedade tem sua inviolabilidade assegurada nos termos da lei e, portanto, possui status de direito fundamental. Vale referir, no entanto, que o direito à propriedade necessita considerar a 
função social e respeitar, naturalmente, as limitações impostas urbanisticamente, visando o bem comum. Sobre esse fato, assim se manifesta Meirelles:

As limitações urbanísticas, sendo medidas de interesse público, atingem indistintamente todos os indivíduos como membros da coletividade administrada. [...] Como imposições de ordem pública, as limitações urbanísticas são imprescritíveis, irrenunciáveis e intransacionáveis por acordo entre as partes, ou mesmo pela aceitação tácita de certas situações de fato. Como as demais imposições do Poder Público, as urbanísticas nascem revestidas de imperium, inerente a toda ordem estatal, tornando-se obrigatórias não só para os particulares como para a própria Administração, visto que a submissão dos indivíduos e das autoridades às normas legais constitui peculiaridade dos Estados de Direito como o nosso. [...] As limitações urbanísticas, como as administrativas, se embasam no art. 170, III, da CF, que condiciona a utilização da propriedade à sua função social. São, portanto, limitações de uso da propriedade, e da propriedade em sua substância; são limitações ao exercício de direitos individuais, e não aos direitos em si mesmos. (MEIRELLES, 2000, p. 438)

O direito individual à propriedade, portanto, não legitima o cidadão a desrespeitar a legislação. Acrescente-se que o direito de propriedade há de coexistir com a sua respectiva função social, porquanto "a propriedade não poderá ser utilizada da maneira desejada unicamente pelo proprietário", afirma Machado (2015, p. 143).

Sobre a função social da propriedade, Sundfeld afirma que:

Como se vê, ao acolher o princípio da função social da propriedade, o Constituinte pretendeu imprimir-lhe uma certa significação pública, vale dizer, pretendeu trazer ao Direito privado algo que até então era tido por exclusivo do Direito Público: o condicionamento do poder a uma finalidade. Não se trata de extinguir a propriedade privada, mas de vinculá-la a interesses outros que não os exclusivos do proprietário. (SUNDFELD, 1987, p. 05)

Ressalva-se que o reconhecimento da função social da propriedade privada difere de ter a mesma um fim social. Não se pode confundir fim e função, uma vez que quando se trata do primeiro está se delimitando sua destinação a um exercício único e imutável, enquanto que o segundo está diretamente ligado ao histórico e também ao futuro concreto mediante situações que ocorrerão ligadas às mais diversas conjunturas. A função, portanto, está ligada à eficácia no ordenamento jurídico existente.

A inclusão territorial, por sua vez, é conceito importante de ser levado em conta posto que entendida como objetivo de assegurar o acesso à terra urbanizada, bem localizada, além de 
garantir a posse segura e precisa da moradia nas áreas ocupadas por população de baixa renda. Não é difícil perceber, portanto, que a inclusão territorial de grupos que ocupam, irregular ou clandestinamente, determinada área não envolve somente questões de cunho fundiário. Torna-se necessário mencionar a relevância do planejamento como mais um conceito intrínseco aos aspectos relevantes do tema. Invoca-se, aqui, uma definição de Ferrari:

Planejamento é um método de aplicação contínuo e permanente destinado a resolver racionalmente os problemas que afetam uma sociedade situada em determinado espaço, em determinada época, através de uma previsão ordenada capaz de antecipar suas ulteriores consequências. (FERRARRI, 1977, p. 03)

Veja-se, ainda, a reflexão de Resende \& Castor (2006) sobre a noção de planejamento:

O Planejamento identifica as vocações locais e regionais, estabelece as regras de ocupação de solo, define as principais estratégias e políticas do município e explicita as restrições, as proibições e as limitações que deverão ser observadas para manter e aumentar a qualidade de vida para seus munícipes. (p. 01).

Tratando ainda de planejamento, Villaça questiona:

[...] essa ação real do Estado brasileiro sobre o urbano insere-se no âmbito do que tem sido recentemente chamado no Brasil de planejamento urbano? [...] a resposta é negativa, pois o objetivo dos planos federais de saneamento, transportes ou habitação não foi - e nem podia ser - a organização do espaço intra-urbano. $O$ conceito dominante de planejamento urbano entre nós tem como especificidade a organização do espaço urbano (embora possa não se limitar a isso) e aplica-se ao plano de uma cidade individualmente. (VILLAÇA, 1999, p. 172)

Relevante ressaltar, ainda, que o conceito de planejamento difere substancialmente do conceito de gestão. Na concepção de Souza,

Planejamento e gestão não são termos intercambiáveis, por possuírem referenciais temporais distintos e, por tabela, se referirem a diferentes tipos de atividade. Até mesmo intuitivamente, planejar sempre remete ao futuro: planejar significa tentar prever a evolução de um fenômeno ou, para dizê-lo de modo menos comprometido com o pensamento convencional, tentar simular os desdobramentos de um processo, com objetivo de melhor precaver-se contra prováveis problemas ou, inversamente, com o fito de melhor tirar partido de 
prováveis benefícios. De sua parte, gestão remete ao presente: gerir significa administrar uma situação dentro dos marcos dos recursos presentemente disponíveis e tendo em vista as necessidades imediatas. O planejamento é a preparação para a gestão futura. (SOUZA, 2002, p. 460)

Do ponto de vista jurídico, o planejamento é entendido como um processo técnico de transformação da realidade visando o cumprimento de objetivos previamente estabelecidos. Antigamente, o processo dependia apenas da vontade do administrador, que poderia utilizá-lo ou não. Não se fazia, portanto, como uma obrigação uma vez que o processo de planejamento encontra fundamentos sólidos na Constituição Federal de 1988 reconhecendo, no art. 21, IX, a competência da União para elaborar e executar planos nacionais e regionais de ordenação do território e de desenvolvimento econômico e social, quando, no art. 174, $\S 1^{\circ}$, inclui o planejamento entre os instrumentos de atuação do Estado no domínio econômico, ou, ainda, quando, mais especificamente, atribui aos Municípios competência para estabelecer o planejamento e os planos urbanísticos para ordenamento do seu território, no art. 30, VIII, e art. 182.

Assim, o planejamento não é mais um processo que depende da vontade do gestor_mas, sim, um processo com previsão constitucional, portanto uma obrigação imposta ao governante.

\section{Método de pesquisa}

A metodologia empregada para se atingir o resultado consistiu em pesquisa qualitativa baseada em revisão bibliográfica, pesquisa documental e observação direta e circunstancial da realidade abordada, de caráter exploratório, objetivando unir a legislação sobre o tema e os instrumentos, bem como sua efetividade, aplicados pelo poder público municipal para solucionar a questão ${ }^{15}$.

A coleta de dados junto à Comunidade Vila do Arvoredo e de documentação junto à Prefeitura Municipal de Florianópolis foi realizada no ano de 2016. As oportunidades não consistiram em apenas ver ou ouvir, mas também em examinar fatos e fenômenos que se pretendia conhecer. Por exemplo, como eram oferecidos pelo município os serviços essenciais à população. O contato com a Comunidade auxiliou na identificação de fatos

\footnotetext{
${ }^{15}$ Como fundamentação da opção metodológica, devem-se registrar os trabalhos de Goode \& Hatt, 1972; Becker, 2007; Goldenberg, 2003; Minayo, 2001 e Haguette, 2005.
} 
sobre os quais os indivíduos não tinham consciência, mas que orientam o comportamento do grupo. A observação direta de elementos objetivos daquela realidade permitiu levantar indicadores para delimitação dos problemas sociais, aproximou o olhar científico da perspectiva dos sujeitos, possibilitou a obtenção de dados sem que houvesse interferência no grupo observado e, sobretudo, permitiu a evidenciação de dados não previstos no roteiro de observação. Por meio de uma observação não estruturada foi possível recolher e registrar fatos da realidade considerada sem a necessidade da utilização de meios técnicos - já que o objetivo proposto não implicava em um nível muito acurado de detalhamento.

Neste sentido, tratou-se, inicialmente, de localizar e apresentar as características da comunidade e explicitar como a ocupação se fez presente, além de tratar da legislação aplicável e da ausência de planejamento e de fiscalização efetiva que geram o embate entre as competências do Poder Executivo e Poder Judiciário para a regularização das ilegalidades.

\section{Resultados}

É possível afirmar que a ocupação na região das dunas de Ingleses, a qual se estende até o presente momento, foi e continua sendo em decorrência da omissão do Poder Executivo local.

O Poder Judiciário, diante de toda sorte de normas e obrigações existentes para planejar, proteger e gerir o espaço público, ante à existência da ocupação da Vila do Arvoredo, é impelido a resolver uma questão de alta complexidade, de intenso impacto social, negligenciada pelo Poder Executivo. Não é aceitável que o Judiciário defina, portanto, o critério de conveniência ou de oportunidade relativo aos atos praticados no exercício da competência do Executivo.

Os atos discricionários ${ }^{16}$ devem ser observados pelo gestor, em razão da forma como a matéria foi regulada pela lei e deve considerar, naturalmente, as circunstâncias que estão postas no caso em concreto. Desta forma, haverá a devida análise subjetiva para o esperado cumprimento da finalidade legal baseada, portanto, em um certo grau de liberdade que, preenchido de acordo com o juízo pessoal e subjetivo do agente, atende, por completo, a finalidade da lei.

\footnotetext{
${ }^{16}$ Os atos administrativos são classificados em: ato vinculado, que é advindo especificamente da lei e ato discricionário que contém um certo grau de subjetividade para a aplicação da norma.
} 
Considerando, hipoteticamente, a interferência do Judiciário para a defesa do meio ambiente, a responsabilidade quanto aos planos e sua efetividade para a urbanização do território e oferecimento de infraestrutura básica à população, além das garantias fundamentais previstas constitucionalmente, a obrigação do poder executivo municipal permanece.

A situação das famílias que residem nas dunas de Ingleses é tocante. Contudo, apesar da moradia ser um importante direito social constitucionalmente previsto, não há de ser considerado como absoluto, como já visto.

\section{Análise e discussão dos resultados}

Avaliando os direitos envolvidos, a questão que se coloca é: entre o direito do meio ambiente ecologicamente equilibrado e o direito à moradia, é possível afirmar que há prevalência de um sobre o outro?

Teoricamente, a salvaguarda do direito ao meio ambiente imposto à coletividade para as presentes e futuras gerações parece se impor, uma vez que também atingiria as famílias ocupantes e suas gerações futuras. Ocorre que o Município é competente para disciplinar o uso do solo, conforme a Constituição Federal em seu art. 30, VIII, pois objetiva a proteção do interesse da cidade. Assim sendo, é o ente político que deveria primar pela fiscalização da forma de ocupação, fato esse que não se verifica nas dunas da Praia dos Ingleses, definidas, inclusive, pela lei local como área a ser protegida.

A ocupação ilegal e formação da comunidade Vila do Arvoredo é apenas representativa de um conjunto de outras ocupações espalhadas pela llha de Santa Catarina e mostra, sobretudo, a inércia do ente municipal. Não há dúvidas quanto à competência do Município que, em conjunto com a sociedade interessada, deveria definir a política urbana, respeitando o princípio da legalidade referente à legislação ambiental e urbanística. Após a definição das formas de ocupação de suas áreas, ao Município, de igual modo, incumbe fiscalizar o cumprimento das diretrizes locais, exercendo o poder de polícia que lhe é atribuído.

Considerando os aspectos jurídicos envolvidos na ocupação da área das dunas de Ingleses e a possibilidade de impacto ambiental real gerado pela ocupação, entende-se que as medidas para impedir, minimizar, salvar ou remediar a situação deveriam ter sido tomadas pelo próprio Município uma vez que deveriam fazer parte de um planejamento municipal cuja importância e eficácia somente o Executivo pode mensurar. 
Não caberia, assim, ao Poder Judiciário tomar todas as providências necessárias para uma regularização total da área visando à proteção do meio ambiente e de todos os direitos envolvidos na ocupação das famílias. Além de descumprir o Pacto Federativo, tomando as rédeas de uma situação que cabe ao Município definir, segundo suas políticas públicas, o Judiciário, certamente, não teria capacidade ou competência para compreender, dentro da vasta possibilidade de planejamento e gestão, as medidas mais adequadas ao caso em questão, mas tão somente apontar e determinar o cumprimento de regras que, descoladas da realidade administrativa municipal, pouca ou nenhuma eficácia teriam.

Dessa forma, tem-se que tamanha negligência com relação à ocupação nas dunas de Ingleses não pode ser remediada com qualquer medida corretiva pela via judicial, uma vez que a complexidade da situação e o altíssimo impacto social não recomendariam, por exemplo, demolições peremptórias de todas as residências o que, naturalmente, representaria medida desproporcional.

A melhor forma de solucionar a questão parece ser, assim, o planejamento de meios viáveis de recuperação da área de preservação envolvendo as residências, cabendo essas providências, precipuamente, ao Poder Executivo, segundo a Constituição Federal em seu art. 23, VI. O cumprimento de tais providências está proibido, no texto da lei, de ser postergado ou negligenciado porque, como visto, não é dado ao administrador optar pela não aplicação ou pela não fiscalização do cumprimento das leis.

É neste sentido que o Ministério Público poderá compelir o Poder Público a agir, fazendoo cumprir as regras impostas e obrigando-o a encontrar solução viável para a gestão do território. Por isso, é importante fazer referência ao princípio do controle judicial dos atos administrativos. Conforme Mello,

É ao Poder Judiciário e só a ele que cabe resolver definitivamente sobre quaisquer litígios de direito. Detém, pois, a universalidade da jurisdição, quer no que respeita à legalidade ou à consonância das condutas públicas com atos normativos infralegais, quer no que atina à constitucionalidade delas. Neste mister, tanto anulará atos inválidos, como imporá à Administração os comportamentos a que esteja de direito obrigada, como proferirá e imporá as condenações pecuniárias cabíveis. (MELLO, 2007, p. 116)

No Brasil, infelizmente, mesmo com a existência de uma legislação constitucionalmente avançada, as políticas públicas e sua aplicação encontram-se ainda incipientes, muito longe da 
necessidade da população e do discurso dos gestores. Sobre a aplicação das políticas públicas, além do acompanhamento e fiscalização do Ministério Público, é preciso haver uma fiscalização rigorosa por parte da sociedade civil organizada, conforme acredita Araújo (1997, p.123).

\section{Considerações finais}

Em que pese todas as tentativas da administração municipal para a solução da ocupação ilegal nas dunas de Ingleses, nenhuma foi, de fato, representativa ou substancial a ponto de alterar a situação que permanece se consolidando e se complexificando.

Depois de algumas de suas casas serem engolidas pela areia, João conseguiu um terreno mais distante das maiores dunas. Desta vez, não pagou pela terra. Afirma apenas que fez um acordo com a fiscalização municipal para permanecer no local sem ser incomodado. Não esclareceu, porém, qual seria a sua contrapartida nesse acordo e vive, como os demais, aguardando uma solução definitiva para o problema.

Maria necessitará mudar-se pela quinta vez, já que o telhado da casa onde vive está comprometido e a proximidade de uma das muitas dunas ameaça constantemente ultrapassar a porta.

João e Maria acreditam na solução pacífica do problema. Eles esperam dias melhores, dias em que terão seus direitos básicos atendidos, em que haverá normas que os resguardem, dias em que, finalmente, sairão de uma área proibida e insalubre. Note-se, no entanto, que a motivação para o imbróglio não seria a falta de normatização, mas, sim, a persistente ineficácia que se renova e fortalece com a omissão e complacência do poder público municipal. 


\section{Referências}

ARAÚJO, Ubiracy. Notas sobre a política nacional do meio ambiente. Revista de Direito Ambiental, Distrito Federal, n. 7, ano 2, p. 119-131, 1997.

BECKER, Howard S. Segredos e truques da pesquisa. Rio de Janeiro: Zahar, 2007.

BRASIL. Decreto-Lei $\mathbf{n}^{\circ} 3.438$, de 17 de julho de 1941. Esclarece e amplia o decreto-lei ${ }^{\circ} 2.490$, de 16 de agosto de 1940. Disponível em: http://www.planalto.gov.br/ccivil_03/decreto-Lei/19371946/Del3438.htm. Acesso em: 05.08.2018.

BRASIL. Lei $\mathbf{n}^{\circ}$ 5.172, de 25 de outubro de 1966. Dispõe sobre o Sistema Tributário Nacional e institui normas gerais de direito tributário aplicáveis à União, Estados e Municípios. Disponível em: http://www.planalto.gov.br/Ccivil_03/Leis/L5172.htm. Acesso em: 05.08.2018.

BRASIL. Lei $\mathrm{n}^{\circ} 6.938$ de 31 de agosto de 1981. Dispõe sobre a Política Nacional do Meio Ambiente, seus fins e mecanismos de formulação e aplicação, e dá outras providências. Disponível em: http://www.planalto.gov.br/ccivil_03/Leis/L6938.htm. Acesso em: 05.08.2018.

BRASIL. Constituição Federativa da República do Brasil. 1988. Disponível em: http://www.planalto.gov.br/ccivil_03/constituicao/constituicao.htm. Acesso em: 05.08.2018.

BRASIL. Lei Federal ${ }^{\circ} 11.977$ de 7 de junho de 2009. Dispõe sobre o Programa Minha Casa, Minha Vida - PMCMV e a regularização fundiária de assentamentos localizados em áreas urbanas; altera o Decreto-Lei $n^{\circ} 3.365$, de 21 de junho de 1941 , as Leis $n^{\text {os }} 4.380$, de 21 de agosto de 1964, 6.015, de 31 de dezembro de 1973, 8.036, de 11 de maio de 1990, e 10.257, de 10 de julho de 2001, e a Medida Provisória $\mathrm{n}^{\circ}$ 2.197-43, de 24 de agosto de 2001; e dá outras providências. Disponível em: http://www.planalto.gov.br/ccivil_03/_at02007-2010/2009/lei/l11977.htm. Acesso em: 05.08.2018.

BRASIL. Lei $\mathbf{n}^{\circ} \mathbf{1 2 . 6 5 1}$, de 25 de Maio de 2012. Dispõe sobre a proteção da vegetação nativa; altera as Leis $n^{\text {os }} 6.938$, de 31 de agosto de 1981, 9.393, de 19 de dezembro de 1996, e 11.428, de 22 de dezembro de 2006; revoga as Leis $\mathrm{n}^{\mathrm{0s}} 4.771$, de 15 de setembro de 1965, e 7.754, de 14 de abril de 1989, e a Medida Provisória no 2.166-67, de 24 de agosto de 2001; e dá outras providências. Disponível em: http://www.planalto.gov.br/cciviL_03/_Ato2011-2014/2012/Lei/L12651.htm. Acesso em: 05.08.2018.

BRASIL. Lei Federal $\mathbf{n}^{\circ} \mathbf{1 3 . 4 6 5}$, de 11 de julho de 2017. Dispõe sobre a regularização fundiária rural e urbana, sobre a liquidação de créditos concedidos aos assentados da reforma agrária e sobre a regularização fundiária no âmbito da Amazônia Legal; institui mecanismos para aprimorar a eficiência dos procedimentos de alienação de imóveis da União; altera as Leis $n^{0 \mathrm{~s}} 8.629$, de 25 de fevereiro de 1993, 13.001, de 20 de junho de 2014, 11.952, de 25 de junho de 2009, 13.340, de 28 de setembro de 2016, 8.666, de 21 de junho de 1993, 6.015, de 31 de dezembro de 1973, 12.512, de 14 de outubro de 2011, 10.406, de 10 de janeiro de 2002 (Código Civil), 13.105, de 16 de março de 2015 (Código de Processo Civil), 11.977, de 7 de julho de 2009, 9.514, de 20 de novembro de 1997, 11.124, de 16 de junho de 2005, 6.766, de 19 de dezembro de 1979, 10.257, de 10 de julho de 2001, 12.651, de 25 de maio de 2012, 13.240, de 30 de dezembro de 2015, 9.636, de 15 de maio de 1998, 8.036, de 11 de maio de 1990, 13.139, de 26 de junho de 2015, 11.483, de 31 de maio de 2007 , e a 12.712, de 30 de agosto de 2012, a Medida Provisória $\mathrm{n}^{\circ}$ 2.220, de 4 de setembro de 2001, e os Decretos-Leis $\mathrm{n}^{\text {os }} 2.398$, de 21 de dezembro de $1987,1.876$, de 15 de julho de 1981, 9.760, de 5 de setembro de 1946, e 3.365, de 21 de junho de 1941; revoga dispositivos da Lei Complementar $n^{\circ} 76$, de 6 de julho 
de 1993, e da Lei nº 13.347, de 10 de outubro de 2016; e dá outras providências. Disponível em: http://www.planalto.gov.br/Ccivil_03/_Ato2015-2018/2017/Lei/L13465.htm. Acesso em: 05.08.2018.

DALVI, Luciano. Curso de direito constitucional. Florianópolis: Conceito Editorial, 2008.

DAWALIBI, Marcelo. O poder de polícia em matéria ambiental. Revista de Direito Ambiental, n. 14, ano 4, Brasília, p. 92-112, 1999.

FERRARI, Célson. Curso de planejamento municipal integrado. São Paulo: Pioneira Editora, 1977.

FLORIANÓPOLIS. Decreto $\mathrm{n}^{\circ} 112$ de 31 de maio de 1985. Tomba as dunas de ingleses, Santinho, Campeche, Armação do Pântano do Sul e Pântano do Sul, no Município de Florianópolis.

Disponível em: https://leismunicipais.com.br/a/sc/f/florianopolis/decreto/1985/11/112/decreto-n-1121985-tomba-as-dunas-de-ingleses-santinho-campeche-aracao-do-pantano-do-sul-e-pantano-do-sulno-municipio-de-florianopolis. Acesso em: 05.08.2018.

FLORIANÓPOLIS. Lei Complementar n ${ }^{\circ} 482$ de 17 de janeiro de 2014. Institui o Plano Diretor de Urbanismo do Município de Florianópolis que dispõe sobre a Política de Desenvolvimento Urbano, o Plano de Uso e Ocupação, os Instrumentos Urbanísticos e o Sistema de Gestão. Disponível em: https://leismunicipais.com.br/a1/plano-de-zoneamento-uso-e-ocupacao-do-soloflorianopolis-sc. Acesso em: 05.08.2018.

GOLDENBERG, Mirian. A arte de pesquisar. 7. ed. Rio de Janeiro: Record, 2003.

GOODE, William J. ; HATT, Paul K. Métodos em pesquisa social. 4 ed. São Paulo: Nacional, 1972.

GRANDO, Sílvia Eloiza. A territorialização em saúde como instrumento para a vigilância em saúde na comunidade Vila do Arvoredo - Ingleses. 2011. Dissertação |(mestrado em Planejamento Territorial e Desenvolvimento Socioambiental) - PPGPLAN/UDESC, Florianópolis, 2011.

HAGUETTE, Tereza Maria Frota. Metodologias qualitativas na sociologia. 10. ed. Petrópolis: Vozes, 2005.

MACHADO, Paulo Affonso Leme. Direito ambiental brasileiro. 23. ed. São Paulo: Malheiros, 2015.

MEIRELLES, Hely Lopes. Direito municipal brasileiro. 11. ed. São Paulo: Malheiros, 2000.

MEIRELLES, Hely Lopes. Direito ambiental brasileiro. 15. ed. São Paulo: Malheiros, 2007.

MELLO, Celso Antônio Bandeira de. Curso de direito administrativo. 23. ed. São Paulo: Malheiros, 2007.

MINAYO, Maria Cecília de Souza (Org.). Pesquisa social: teoria, método e criatividade. 18. ed. Petrópolis: Vozes, 2001.

REZENDE, Denis. Alcides; CASTOR, B.V.J. Planejamento estratégico municipal: empreendedorismo participativo nas cidades, prefeituras e organizações públicas. Rio de Janeiro: Brasport, 2006.

SILVA, José Afonso da. Direito urbanístico brasileiro. 34. ed. São Paulo: Malheiros, 2006. 
SILVA, José Afonso da. Curso de direito constitucional positivo. 32. ed. São Paulo: Malheiros, 2009.

SOUZA, Marcelo Lopes de. Mudar a cidade: uma introdução crítica ao planejamento e à gestão urbanos. Rio de Janeiro: Bertrand Brasil, 2002.

SUNDFELDE, Carlos Ari. Função social da propriedade. In: DALLARI, Adilson Abreu, Temas de direito Urbanístico. São Paulo: Ed. RT, 1987, p. 01 -22.

VILLAÇA, Flávio. O processo de urbanização no Brasil. In: SCHIFFER, Sueli Ramos, Uma contribuição para a história do planejamento urbano no Brasil. São Paulo: Editora da Universidade de São Paulo, 1999, p. 169-244. 